Современная стратегия диагностики, лечения, профилактики сахарного диабета и его осложнений. Стандартные и инновационные методы контроля гликемии. Командный подход к лечению и профилактике острых и хронических осложнений сахарного диабета.

\title{
ДИНАМИКА УРОВНЯ АУТОАНТИТЕЛ К ДОФАМИНОВЫМ И МЕЛАТОНИНОВЫМ РЕЦЕПТОРАМ У ДЕТЕЙ И ПОДРОСТКОВ С ХРОНИЧЕСКИМ ТЕЧЕНИЕМ САХАРНОГО ДИАБЕТА 1 ТИПА
}

\author{
'Быков Ю.В., ${ }^{2}$ Батурин В.А. \\ 'ФГБОУ ВО «Ставропольский государственный медицинский университет» Минздрава России, Ставрополь \\ ${ }^{2}$ ФГБОУ ВО «Ставропольский государственный медицинский университет» Минздрава России, Ставрополь
}

ЦЕЛЬ: оценить содержание аутоантител к мелатониновым и дофаминовым рецепторам у детей с сахарным диабетом (СД) І типа на фоне хронического течения.

МАТЕРИАЛЫ И МЕТОДЫ: в данное исследование были включены дети в возрасте от 2 до 17 лет. Обследовано 76 детей с длительным (хроническим) течением СД Ітипа (средняя длительность заболе-

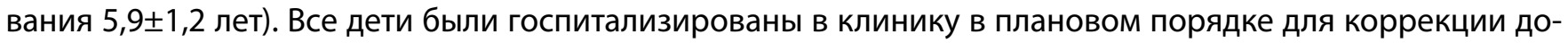
зировки препаратов инсулина. Забор венозной крови проводили в день поступления, в утренние часы. Методом ИФА (тест-системы НПО «Иммунотэкс», Россия) определяли уровень аутоантител lgG (AАT) к мелатониновым и дофаминовым рецепторам (DR2) в сыворотке крови. Полученные данные подвергались статистическому анализу с применением пакета программ STATISTICA.

PЕЗУЛЬТАТЫ: содержание ААТ к мелатониновым рецепторам в сыворотке крови детей больных СД

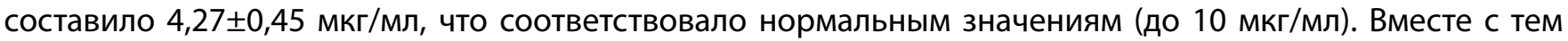

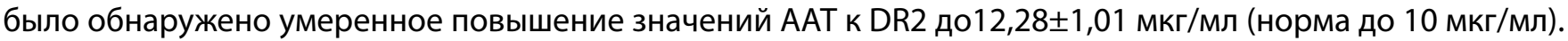
При оценке значений AAT к DR2, было выявлено, что показатели AAT, которые превышали норму, были зафиксированы у детей, поступивших стационар в тяжелом состоянии, в то время как дети с СД I типа, имевшие нормальные показатели AAT к DR2, поступали в состоянии средней степени тяжести.

Выводы: определение уровня ААТ к мелатониновым и дофаминовым рецепторам (DR2) может быть использовано для оценки длительности течения СД I типа у детей. При этом более высокие показатели AAT к DR2, характерны для более тяжелого клинического состояния детей с данной патологией.

КЛЮЧЕВЫЕ СЛОВА: сахарный диабет; аутоантитела; дофаминовые рецепторы; мелатониновые рецепторы. 